although the particular moulded member is composite, the resulting effect is that of solid timber, incidentally possessing extremely durable properties; since the structure of the unit is composite, inherent stresses natural to solid timber are reduced; there is little or no prospect of cracking or splitting. This publication describes and illustrates this type of work as carried out by Ebdons (Beddington), Ltd., of Croydon, who have had long experience of building church furniture and selecting the best possible timber for conditioning by kiln drying for this special purpose. Examples of this skilled workmanship in glued timber structures as shown includo churches and chapels in Belham, Bromley, Walworth, Sutton and Cheam, Harting near Petersfield, and Eridge Castlo, Sussex.

The use of 'Araldite' in bonding metal to woodwork is exemplified in the case of a processional cross (illustrated) which ". . . has the shaft reinforced with a steel rod bonded with Araldite epoxy resin. The same adhesive is used for the bonding of metal fittings on communion rails, chairs, lecterns, etc.". In a later issue of Ciba Technical Notes $\dagger$, an account is given of the use of "Araldite in Electron Microscopy". In this field it is used as an embedding medium of great stability. In the examination of animal and plant tissues with an ordinary laboratory microscope, paraffin wax is the standard embedding compound from which the requisite thin sections are cut by microtome; but with the electron microscope, exceptionally thin sections are required, and certain synthetic resins have been investigated. According to a report by Miss Audrey M. Glauert, Strangeways Research Laboratory, Cambridge, on which these technical notes are based, ". ... formulations based on Araldite epoxy resins have been found to be eminently successful, and such formulations have been adopted in research laboratories throughout the world".

H. B. MHLNER

† No. 263. Pp. 8. (Duxford: Ciba (A.R.L.), Ltd., 1964.)

\title{
PHOTO-NEURO-ENDOCRINE EFFECTS IN CIRCADIAN SYSTEMS
}

$I_{\mathrm{r}}^{\mathrm{T}}$ is well established that the exact timing of 24-h rhythms is dependent on environmental influences, and that when all such influences are removed, although the rhythm may persist it is no longer synchronous with solar time but becomes free-running with a periodicity of anything between 20 and $28 \mathrm{~h}$. The importance of the influence of daily changes of light and darkness on many daily and seasonal rhythms in both sickness and health has been recognized, if only dimly, since the times of Hippocrates. A great deal is now known about this influence of light on physiological processes and of the neuro-endocrine pathways involved. The Proceedings of a symposium on "Photo-Neuro-Endocrine Effects in Circadian Systems, with Particular Reference to the Eye"* comprise a comprehensive survey, by the workers eoncerned, of the more recent additions to this knowledge. While there is some evidence that light waves, when they can penetrate sufficiently deeply, may act directly on hypothalamic structures in both avian and mammalian species, the more general influence of light on the sympathetic system is through a specific nervous pathway from the eye to the hypothalamus. Through the hypothalamic-hypophyseal connexions light can influence the endocrine discharges from the pituitary lobes. It is not surprising, then, to learn that the intensity and duration of light exposure can influence a great number of sympathetically and hormonally controlled physiological functions, particularly those of body temperature, reproduction and metabolism.

Halberg's term 'circadian', to describe the de-synchronized or free-running endogenous rhythmicity of only approximately $24 \mathrm{~h}$, is now generally accepted, at least in North America, and is clearly defined in the course of Dr. Hague's opening remarks. In some of the subsequent papers, however, no sharp distinction is made between the terms 'diurnal' (when used to describe a rhythm or activity over a period of $24 \mathrm{~h}$ ) and 'circadian'. In a paper by Halberg and others, the term 'circadian' is extended to include "the special case of an exact 24-h period". This is consistent with Halberg's use, in another paper, of the word 'diurnal' in the more fundamental sonse to describe an activity in relation to day-time, as opposed to 'nocturnal' and 'night-time'. Whether the term 'diurnal activity' used elsewhere in the volume describes an activity restricted to the day-time, or

* Annals of the New York Academy of Sciences. 117, Article 1: PhatoNeuro-Endocrine Effects in Circadian Systems, with Particular Reference to the Eye. By E. B. Hague and 64 other during a 24-h period, is not at all clear. This is most confusing. In view of the stricture made on the use of the word 'circadian' by Williams in $1963^{1}$, it would be well if agreement could be reached on the use of these terms. We now have three distinct words and three distinct, or distinguishable, meanings which could be used as follows: (I) diurnal, that is, pertaining to the day-time, the complement to 'nocturnal'; (2) nychthemeral (or nycthemeral, as used by French-speaking biologists), that is, relating to solar time, a period of $24 \mathrm{~h}$, consisting of a night and a day (Shorter Oxford English Dictionary); (3) circadian, that is, the description of an approximately 24-h free-running endogenous rhythmicity. Perhaps the ambiguity of 'diurnal' is too deeply rooted for any plea for its eradication to be heard, but if the new term 'circadian' is to be wholly acceptable, its meaning must be made perfectly elear.

As is often the case with Proceedings of symposia by students of many disciplines and from many countries, this volume is not uniformly easy to assimilate, but it quickly arouses and sustains the interest of the reader. Strictly verbatim reporting of discussions can be irritating, especially when accompanying slides are not reproduced as figures. There is clear evidence, in at least one paper, of considerable alteration to the text subsequent to its original presentation. This would seem to destroy the whole premise for verbatim reporting elsewhere, and careful editing would not have obscured the valuable points which were sometimes raised in discussion. However, the symposium was well conceived, and was well balanced between the fundamental biological significance of the influence of light on physiological processes, and its considerable medical importance. While the subjectmatter of some of the papers is not strictly within the terms of reference given in the title of the symposium, they afford a broader understanding of other inter-related factors which should not be ignored in a study of specific physiological processes. Papers on autonomic conditioning and the hypothalamic-hypophyseal neural influence in periodic diseases, for example, give depth to the more general consideration of the nature of biological rhythms, in both normal and abnormal conditions, while the two papers on control theory in relation to biological systems have even wider application and interest. This volume will be a valuable source of information for some long time to come.

JOHN BLIGH

Press, London, 1963). 